\title{
Short-term and procedural memory for colours and inferior temporal cortex activity
}

\author{
E. Castro-Sierra ${ }^{1}$, E. Paredes-Díaz ${ }^{2}$ and J.A. Lazareff ${ }^{3}$ \\ 'Laboratory of Psychoacoustics, ${ }^{2}$ Department of Neurosurgery, Hospital Infantil de México, \\ México and ${ }^{3}$ Division of Neurosurgery, UCLA School of Medicine, Los Angeles, CA 90024, USA \\ Correspondence to: Eduardo Castro-Sierra, Laboratory of Psychoacoustics, Hospital Infantil de \\ México, Dr Márquez No. 162, 06720 México, D.F., México
}

\begin{abstract}
Two children (male, 10 years, and female, 13 years one month) with tumours of the inferior temporal (IT) cortex of the brain were studied post-surgically for their abilities to carry out a short-term memory test. This involved: differences in colour, number and shape of small plastic objects; differences in receptacles where these objects should be placed and in ways in which this placement should be done; a procedural task involving differences either in colour or in size of wooden rings employed in the task. Their performances in these tests, and those of patients with tumours of other encephalic areas, were compared with the performances of normal controls. The subjects with IT tumours spent a significantly greater amount of time than normal subjects of their age in carrying out the procedural task involving differences in colour. One of the IT subjects also spent a significantly greater amount of time in the procedural task involving size differences. Other differences in the performances of patients with encephalic tumours and the performances of normal controls were not significant. Results are discussed in relation to findings of colour and size perception and memory localized to the inferior temporal and middle temporal cortices.
\end{abstract}

Keywords: Colours - Inferior temporal cortex - Procedural learning - Short-term memory

\section{INTRODUCTION}

Corbetta et al. (1991) using PET have found that area 17 of Brodmann, i.e. area V1, the lingual gyrus, the collateral sulcus and the dorsolateral cortex mainly of the left side of the brain are active in colour perception in man. Roland et al. (1990) have employed similar PET techniques to study the activity of different brain regions in responding to presentations of patterned colour stimuli. The latter authors have found that, in conjunction with area V1, the cuneus and precuneus, the occipital gyri, the orbitofrontal cortex, the anterior hippocampus and the anterior half of the neostriatum, both the left and the right temporal pole of normal adults show an increased regional cerebral blood flow ( $\mathrm{rCBF}$ ) when these subjects first learn the patterns but not when they attempt to recall them or to recognize them in later presentations. According to Mishkin (1982), the inferior lateral temporal (IT) cortex, of which the temporal poles form part, is a storehouse for object vision in man as well as in other primates. In this regard, Miyashita (1993) has further

Portions of this article were presented at the 24th Meeting of the Society for Neuroscience, Miami Beach, FL, November, 1994. considered that the occipito-temporal visual pathway from V1 serves as an analyser of the physical properties of a visual object or image, such as size, colour, texture or form, and that the analysed attributes are synthesized at the anterior IT cortex into a specific configuration. This representation of a visual object is flexible and can be acquired in the neural network of IT cortex through visual experience, or learning, in adulthood.

Using delayed non-matching-to-sample techniques, Mishkin and his group at NIH (Mishkin and Petri, 1984; Mishkin et al., 1984; Mishkin and Appenzeller, 1987) have carried out studies of visual short-term memory in macaques with damage to different encephalic structures. These researchers have found that ablation of the amygdala and the hippocampus in these monkeys leads to increased deficit levels in tests where an object seen just once must be recognized. However, when the object to be recognized is presented over different sessions to the same subjects whose limbic areas have been removed, activity of the IT cortex, probably in concert with those of specific striatal structures, seems to enable 
the monkeys to carry out the task. Based on the deficits found in these studies, Mishkin and his associates (Mishkin and Petri, 1984; Mishkin et al., 1984) have proposed the existence of two memory systems. According to these authors, the first system, related to recognition memory and to associative recall, involves the limbic circuit, certain parts of IT cortex and other insular and prefrontal areas connected to this circuit. An activation of the limbic circuit results in the storage of a representation of a stimulus configuration within the sensory area, visual, auditory or somatosensory, that triggered the circuit. This neural representation is considered to be later stored in other parts of the memory system to which the sensory cortical areas project. The content of this store is cognitive, i.e. information or knowledge. The second system, related to learning, and requiring repeated exposures to a visual experience, involves the striatum and other parts of IT cortex. Activity within this cortico-striatal system stores the probability that a specific stimulus will evoke a specific response, as a result of reinforcement operating in the situation. This latter system has been called the 'habit', or learning, system by Mishkin.

Saint-Cyr and his associates (1988) at the University of Toronto have investigated some of the features of visual learning in experiments with patients suffering from early forms of Parkinson's disease. These patients show a selective impairment in tasks involving procedural learning, but no deficits in recall or recognition tests of declarative memory. As has been discussed above, although procedural learning seems to relate to the ability of gradually acquiring a motor skill or a cognitive routine after repeated experience with a specific activity constrained by invariant rules, declarative memory appears to refer more to the ability to recall consciously or recognize data present in the form of words, visual images or events. In the studies of Saint-Cyr et al. (1988) patients with Parkinson's disease manifested a deficit in learning a task which involved moving different colour or different size rings, following a specific routine, from left to right on pegs on a plastic board. This type of result contrasted with what was obtained employing the same task among either amnesic patients or some patients with early forms of Huntington's disease. Both of these latter groups of patients had selective deficits in tests of declarative memory but no deficits in the procedural learning task. Nevertheless, some other patients with early forms of Huntington's disease also showed deficits in the latter task. Because the neostriatum and associated structures are damaged in Parkinson's disease, and because early involvement of dopamine-innervated striosomal regions of the caudate nucleus are also known to be damaged in early forms of Huntington's disease, it would seem that these areas are essential for learning cognitive procedures.

Recently, at the Hospital Infantil de México we had the opportunity of studying two children with tumoral pathology of the IT cortex. The first subject, I.A.L., was a 10-year-old boy with an astrocytomaoligodendroglioma of the left temporal pole. The second subject, B.S.M., was a 13-year-old girl with an astrocytoma of the right inferior temporal lobe which affected most of IT, and also other areas of the temporal lobe and cortex. These young subjects, as well as young patients suffering from tumours of other regions of the brain or of the cerebellum, were compared with young normal controls in their abilities to carry out the procedural tasks involving differences in ring colour (Tower of Toronto task) or in ring size (Tower of Hanoi task) utilized by Saint-Cyr and his associates (1988). The patients with non-IT tumours in our study were chosen because their lesions were distantly located from the centres of colour perception and learning in the brain and the neostriatum investigated by Corbetta et al. (1991) and Roland et al. (1990). We hypothesized that procedural learning would be affected in the two subjects of the group with IT tumours and that, given the relevance of IT cortex as a centre of storage of visual characteristics of objects (Mishkin, 1982), they might show increased deficits over those of the control subjects in carrying out the Tower of Toronto (colour) task, even though in the former patients damage was limited to only one side of the brain. IT cortex is at present generally accepted to be active in perception and memory of an object's features, such as colour, pattern or shape. On the other hand, the involvement of IT cortex in perception and memory of the size or position of a certain object relative to those of other objects is at present debated (Ungerleider and Mishkin, 1982; Miyashita, 1993). Thus, we assumed that the results of the IT subjects in the Tower of Hanoi (size) task might also provide us with information concerning the participation of inferior temporal areas of the brain in the perception and memory of spatial relations between visual stimuli.

Although mechanisms of visual short-term recognition memory appear to be located in other areas of the brain besides IT in man, particularly the superior lateral temporal cortex (Cacace et al., 1992) and the frontal cortex (Nielsen-Bohlman and Knight, 1994), in addition to the procedural tasks we used a visual short-term memory test (Lazareff and Castro-Sierra, 
1991), which has a procedural component, to study visual short-term memory abilities in all groups of subjects.

\section{METHODS}

\section{Subjects}

All subjects of this study were participants in a larger investigation of auditory and visual short-term memory abilities in children with cerebellar tumours (Lazareff and Castro-Sierra, 1991) carried out between January 1990 and July 1993 at the Hospital Infantil de México. In that investigation, the subjects were tested exclusively with the short-term memory test described below. The two subjects with IT tumours in the present study on visual short-term and procedural memory abilities in children with tumoural pathology of the inferior temporal cortex arrived at the Hospital in April and June of 1993, respectively, at the end of the investigation on cerebellar memory abilities. Subjects V.C.O., C.H.M., L.D.H. AND J.S.M. were studied shortly after the two subjects with IT tumours and thus were the only others available to undertake the procedural learning tasks also described below.

Subjects of the first, or IT, group were: I.A.L. (male, 10 years 0 months, with astrocytomaoligodendroglioma of the left temporal pole) and B.S.M. (female, 13 years 1 month, with astrocytoma a)

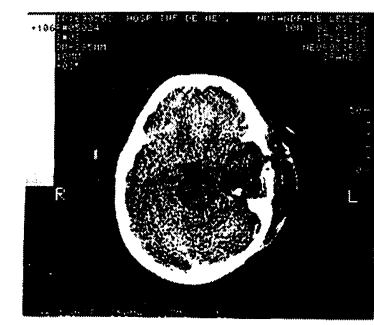

$$
\underset{(m, 10: 0)}{\text { I.A.L. }}
$$

Oligodendroglioma of left temporal pole.

b)

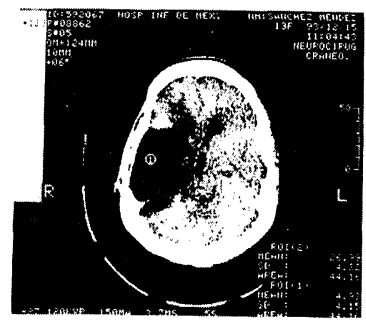

B.S.M

(f, 13:1)

Astrocytoma of right temporal lobe.

FIG.1. Post-surgical contrast axial tomography. $L$ is left and $R$ is right. (a) I.A.L. (male, 10 years 0 months). Note increased density in area of left temporal pole of the brain. (b) B.S.M. (female, 13 years 1 month). Note increased density in area including most of right inferior temporal lobe of the brain.

of the right temporal lobe, which affected most of IT). Post-surgical contrast tomographies of these two subjects' brain lesions are shown in Fig. 1.

Subjects of the second, or cerebellar, group were subdivided into patients with vermal (VER) tumours and patients with hemisphere (HEM) tumours. This

\begin{tabular}{|c|c|c|c|c|c|}
\hline Name & Sex & $\mathrm{Age}^{1}$ & Dx & Resection & Location $^{2}$ \\
\hline I.A.L. & M & $10: 0$ & $\begin{array}{l}\text { Astrocytoma- } \\
\text { oligodendroglioma }\end{array}$ & Left polar temporal lobectomy & $\begin{array}{l}x=-3 \mathrm{~cm} \\
y=3 \mathrm{~cm} \\
z=-4 \mathrm{~cm}\end{array}$ \\
\hline B.S.M. & $\mathrm{F}$ & $13: 1$ & $\begin{array}{l}\text { Microcystic } \\
\text { astrocytoma }\end{array}$ & Right inferior temporal lobectomy & $\begin{array}{l}x=10 \mathrm{~cm} \\
y=-5 \mathrm{~cm} \\
z=4 \mathrm{~cm}\end{array}$ \\
\hline V.C.O. & $\mathrm{F}$ & $5: 11$ & Astrocytoma & Cerebellar vermis & $\begin{array}{l}x=3 \mathrm{~cm} \\
y=-2 \mathrm{~cm} \\
z=-3 \mathrm{~cm}\end{array}$ \\
\hline J.S.A. & M & $15: 6$ & Ependymoma & Cerebellar vermis & $\begin{array}{l}x=-3 \mathrm{~cm} \\
y=-3 \mathrm{~cm} \\
z=-3 \mathrm{~cm}\end{array}$ \\
\hline C.H.M. & M & 10:10 & Astrocytoma & Right cerebellar hemisphere & $\begin{array}{l}x=5 \mathrm{~cm} \\
y=-4 \mathrm{~cm} \\
z=-4.5 \mathrm{~cm}\end{array}$ \\
\hline M.H.F. & M & $11: 11$ & Astrocytoma & Right cerebellar hemisphere & $\begin{array}{l}x=5 \mathrm{~cm} \\
y=-3 \mathrm{~cm} \\
z=-3 \mathrm{~cm}\end{array}$ \\
\hline L.D.H. & M & $8: 3$ & Astrocytoma & Right fronto-parietal area & $\begin{array}{l}x=3 \mathrm{~cm} \\
y=3 \mathrm{~cm} \\
z=4 \mathrm{~cm}\end{array}$ \\
\hline D.M.S. & $\mathrm{F}$ & $12: 10$ & Astrocytoma & Right temporo-parietal area & $\begin{array}{l}x=5 \mathrm{~cm} \\
y=-4 \mathrm{~cm} \\
z=4.5 \mathrm{~cm}\end{array}$ \\
\hline
\end{tabular}

TABLE I. Location and extent of patients' encephalic lesions

${ }^{1}$ Years: months

${ }^{2} x$, left - right; $y$, anterior - posterior; $z$, cephalic - podalic. 
subdivision was considered because results of several studies have stressed the differences underlying the activities of neurones of the central vermis and of the lateral hemispheres of the cerebellum relating to auditory short-term memory and to visual procedural learning, respectively (Lazareff and Castro-Sierra, 1991; Kim et al., 1994). Typically, the age of children with cerebellar VER tumours, especially ependymomas, is around 7 years (Hudson, 1990). Therefore, we were fortunate in having a subject with a VER ependymoma (J.S.A.) whose age was considerably above this limit, and thus in being able to bring up the average age of this subgroup. Subjects of the VER subgroup were: V.C.O. (female, 5 years 11 months, astrocytoma) and J.S.A. (male 15 years 6 months, ependymoma); subjects of the HEM subgroup were: C.H.M. (male, 10 years 10 months, right astrocytoma) and M.H.F. (male, 11 years 11 months, right astrocytoma). Subjects of the third, or supratentorial (ST), group were: L.D.H. (male, 8 years 3 months, right prerolandic astrocytoma) and D.M.S. (female, 12 years 10 months, right parieto-temporal astrocytoma). Subjects of the fourth, or control (CON), group were: J.S.M. (male, 11 years 2 months) and E.V.A. (male, 11 years 3 months). A resumé of the localization and extent of the patients' encephalic lesions is given in Table I. Tests used to assess the intellectual abilities of each subject were the Wechsler Intelligence Scales for Children-Revised (Wechsler, 1974) and the Coloured Progressive Matrices (Raven et al., 1986). Given that it requires the recognition of shapes with different colours by the subject, the latter test was utilized to analyse the colour perception abilities of the children of this study. Results of both tests are given in Table II. Because their response averages in the Raven's matrices were around normal, these data were taken to indicate that none of the subjects suffered from a colour perception defect. All subjects in our study were right-handed.

\section{TESTS AND APPARATUS}

Visual short-term memory test. This test was modified from one employed by Boucher and Lewis (1989) in a study of memory abilities of young autistic subjects in England, and applied at the Hospital Infantil de México to the investigation of visual and auditory short-term memory abilities of children with cerebellar tumours of different aetiologies (Lazareff and Castro-Sierra, 1991). It is related to the delayed matching-to-sample tests in that the test object is presented only once to the subject, who must recall it after a pause given by a distractor task. Because the subject must carry out a simple task with the test object to be recalled, it also includes a procedural component.

Each subject was seated in an isolated room in front of a table and facing the investigator, who was also seated. On the table lay four different receptacles (plastic bag, wicker basket, tin can and large plastic cup), and behind the receptacles and near the

TABLE II. Results of Coloured Progressive Matrices and Wechsler Intelligence Scale tests

\begin{tabular}{|c|c|c|c|c|c|c|}
\hline \multirow[b]{2}{*}{ Group } & \multirow[b]{2}{*}{ Number } & \multirow[b]{2}{*}{$\begin{array}{c}\text { Age }^{1} \\
\text { (mean/range) }\end{array}$} & \multirow[b]{2}{*}{$\begin{array}{c}\text { CPm score }{ }^{2} \\
\text { (mean/range) }\end{array}$} & \multicolumn{3}{|c|}{ WISC-R scaled score ${ }^{3}$} \\
\hline & & & & $\begin{array}{c}\text { Overall } \\
\text { (mean/range) }\end{array}$ & $\begin{array}{c}\text { Verbal } \\
\text { (mean/range) }\end{array}$ & $\begin{array}{l}\text { Performance } \\
\text { (mean/range) }\end{array}$ \\
\hline IT & 2 & $\begin{array}{c}11: 7 \\
(10: 0-13: 1)\end{array}$ & $\begin{array}{c}28.5 \\
(27.9-29.1)\end{array}$ & $\begin{array}{c}8.3 \\
(8.2-8.4)\end{array}$ & $\begin{array}{c}9.0 \\
(8.7-9.3)\end{array}$ & $\begin{array}{c}7.5 \\
(7.2-7.8)\end{array}$ \\
\hline VER & 2 & $\begin{array}{c}10.8 \\
(5: 11-15: 6)\end{array}$ & $\begin{array}{c}28.8 \\
(25.2-32.4)\end{array}$ & $\begin{array}{c}8.5 \\
(7.8-9.2)\end{array}$ & $\begin{array}{c}8.4 \\
(7.6-9.2)\end{array}$ & $\begin{array}{c}8.7 \\
(7.6-9.8)\end{array}$ \\
\hline HEM & 2 & $\begin{array}{c}11: 4 \\
(10: 10-11: 11)\end{array}$ & $\begin{array}{c}29.2 \\
(29.0-29.4)\end{array}$ & $\begin{array}{c}8.8 \\
(8.6-9.0)\end{array}$ & $\begin{array}{c}8.9 \\
(8.8-9.0)\end{array}$ & $\begin{array}{c}8.6 \\
(8.5-8.7)\end{array}$ \\
\hline ST & 2 & $\begin{array}{c}10: 7 \\
(8: 3-12: 10)\end{array}$ & $\begin{array}{c}29.4 \\
(27.3-31.5\end{array}$ & $\begin{array}{c}8.9 \\
(8.4-9.4)\end{array}$ & $\begin{array}{c}9.0 \\
(8.9-9.1)\end{array}$ & $\begin{array}{c}8.6 \\
(8.3-8.9)\end{array}$ \\
\hline CON & 2 & $\begin{array}{c}11: 3 \\
(11: 2-11: 3)\end{array}$ & $\begin{array}{c}30.0 \\
(28.9-31.1)\end{array}$ & $\begin{array}{c}9.1 \\
(9.0-9.2)\end{array}$ & $\begin{array}{c}8.9 \\
(8.6-9.2)\end{array}$ & $\begin{array}{c}9.2 \\
(8.9-9.5)\end{array}$ \\
\hline
\end{tabular}

'Years: months.

${ }^{2} \mathrm{~A}$ score of 29 in the Coloured Progressive Matrices is equivalent to a mental age of approximately 11 years and 3 months.

${ }^{3} \mathrm{~A}$ score between 8 and 10 in the scaled WISC-R we took to be equivalent to a mental age of approximately 11 years with average or normal intelligence.

86 Behavioural Neurology • Vol 10 • 1997 
subject lay four containers with small plastic toys of different colours and shapes. In one of these containers were 12 firemen, in another 12 hooks, in another 12 dogs and in another 12 wheels. Of the toys in each of the containers, three were blue, three red, three green and three yellow. The subject had to put up to three plastic toys of a certain colour and shape in front of, behind, on top of, or under one of the receptacles following manual instructions given by the investigator. The instructions were of the form: "Put two red firemen under the basket" or "Put three green wheels behind the bag". The investigator did this by taking the object(s) and placing it (them) in the prescribed position. After a short pause, he returned it (them) to its (their) original position. Immediately afterwards, the investigator provided oral instructions concerning a distractor task which the subject had to do with one of the different objects on a chair at the side of the table. Examples of the distractor tasks are: taking a pencil from the chair, showing it to the investigator and putting it back on the chair; counting the number of coins on the chair and repeating this aloud to the investigator. The verbal cueing for the distractor tasks was the only oral information given by the investigator to the subject, and the verbal responses to the task were the only ones allowed the subject.

The subject proceeded to carry out the distractor task first and the short-term memory test instruction next. The distractor task was set up merely to increase the memory load of the test; thus, its outcome was of no direct relevance to the outcome of the test itself. There were two sets of 12 different instructions in this part of the test. Either set was chosen at random to be carried out by each subject. This simple part was followed by a more complex one in which the subject was instructed to do two different things, e.g. "Put one blue hook in front of the can and two yellow dogs on top of the cup". Here, again, the subject had to perform a distractor task before carrying out each test instruction. There were two sets of 10 different instructions in this part of the test, and either set was also chosen at random for each subject to carry out. The investigator first ascertained that each subject had understood the test as well as the differences in colour, shape and number of the plastic toys and the differences in receptacles and position. Test trials were begun after three training runs. The number of errors committed by each subject in each condition (i.e. in reference to number, colour and shape of objects and to position and receptacle, in carrying out the total of 22 instructions after the distractor task delay) was employed as a measure of performance.
For example, if the instruction was "Put two red firemen under the basket" and the subject put two red dogs under the basket this was counted as an error in the 'shape' condition; if, on the other hand, the subject put two green dogs under the basket this was counted both as an error in the 'shape' condition and as an error in the 'colour' condition. Because the physical condition of several of the patients did not allow for their being tested before surgery, the results of this test and of the procedural tasks refer to studies undertaken post-surgically, 1-2 weeks after ablation of the tumours, of the subjects of the IT, VER, HEM and ST groups. The subjects of the CON group were studied only once.

Procedural tasks. Each subject again sat in front of the table and facing the investigator. On the table lay a wooden board with three pegs built according to specifications given by Saint-Cyr and his associates in their article (1988). Three wooden rings, which could be any of different colours (white, yellow and red) or of different diameters $(7,8$ and $9 \mathrm{~cm})$, were employed. They were inserted, from top to bottom in the given order, on the leftmost peg on the board. The subject was instructed to move the stack of rings from the leftmost peg, through the middle peg, to the rightmost peg without moving more than one ring at a time. When the rings were of different colours (Tower of Toronto task), the subject was further instructed to abstain from placing a darker colour ring (e.g. yellow) on top of a lighter colour ring (e.g. white); when the rings were of different sizes (Tower of Hanoi task), he/she was instructed to abstain from placing a larger size ring (e.g. $9 \mathrm{~cm}$ ) on top of a smaller size ring (e.g. $8 \mathrm{~cm}$ ). Before starting with the task trials, the investigator ascertained that each subject had understood the task as well as the differences in colour or in size of the rings. Training runs were then begun. Although, originally, Saint-Cyr and his associates had employed up to four rings in these tasks, this proved to be too difficult for the young subjects of the present study to carry out, and the number of rings had to be decreased to three. Moreover, the former authors had counted the number of moves employed by each adult subject in the tasks but, because by using three rings every one of the young subjects could do the tasks in about the same number of moves, the average time spent in three task trials by each subject was now utilized as a measure of performance. Furthermore, because both the patients with Parkinson's disease and the patients with Huntington's disease in the study of Saint-Cyr et al. (1988) had found the Tower of Toronto (colour) task 
easier than the Tower of Hanoi (size) task, the order in which these two tasks were carried out by the subjects of the present study was randomized to minimize precedence effects. Task trials were undertaken by I.A.L. and B.S.M., and by selected subjects from the other groups (V.C.O., C.H.M., L.D.H. and J.S.M.).

\section{RESULTS}

Results of the visual short-term memory test are given in Fig. 2. The histogram shows the number of errors committed by each of the two subjects of each group and subgroup in reference to each of the conditions of the test. Each subject's number of errors was compared with the average number of errors of subjects in the control group. Although both subjects of the IT group made a large number of errors in remembering the colour of objects of the test, the difference in the number of errors made with, reference to the same condition, by the two subjects of the CON group did not reach significance.

A comparison of results in this test, provided in number of standard deviations from the norm, is given in Fig. 3. Results of the procedural learning tasks are given in Fig. 4. The histogram shows the average time spent in three trials of each task by each subject carrying out these tasks. The time spent by each patient in each task was compared with the time spent by the CON subject also in each task. Here, the

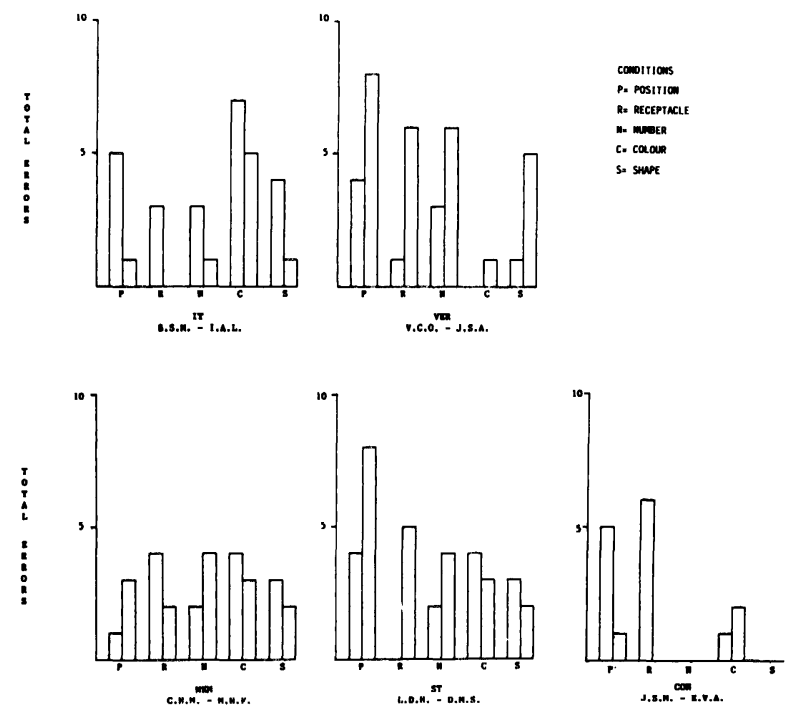

FIG. 2. Histogram showing results of subjects of the IT, VER, HEM, ST and CON groups in visual short-term memory test (Lazareff and Castro-Sierra, 1991). Each column refers to number of errors committed by each of the subjects in reference to each of the five conditions of the test. average time spent in the Tower of Hanoi (size) task by B.S.M. of the IT group was increased over that spent in the same task by J.S.M. of the CON group, and the average time spent in the Tower of Toronto (colour) task by I.A.L. and B.S.M. of the IT group was increased over that spent in the same task by J.S.M. of the CON group. These differences, also provided in number of standard deviations from the norm in Fig. 5, were significant for the Tower of Toronto (colour) task (I.A.L. versus J.S.M.: -7.05 , p $<0.01$, and B.S.M. versus J.S.M.: $-10.69, \mathrm{p}<0.01)$ and for the Tower of Hanoi (size) task (B.S.M. versus J.S.M.: $-4.41, \mathrm{p}<0.01$ ). All other differences in the short-term memory test and in the procedural tasks were not significant.

\section{DISCUSSION}

Results in the Tower of Toronto (colour) task of subjects of the present study with unilateral tumoral lesions of the IT cortex indicate that this region is essential for procedural learning involving differences in colour. Thus, damage to a limited portion of IT cortex of only one side of the brain, i.e. the left temporal pole in subject I.A.L., was sufficient to cause significant deficits in a procedural learning task. The anterior, or TE, part of the IT region sends afferent connections to the amygdala (Baizer et al., 1991) which, in turn, makes contact with the dorsomedial nucleus of the thalamus through the ventral

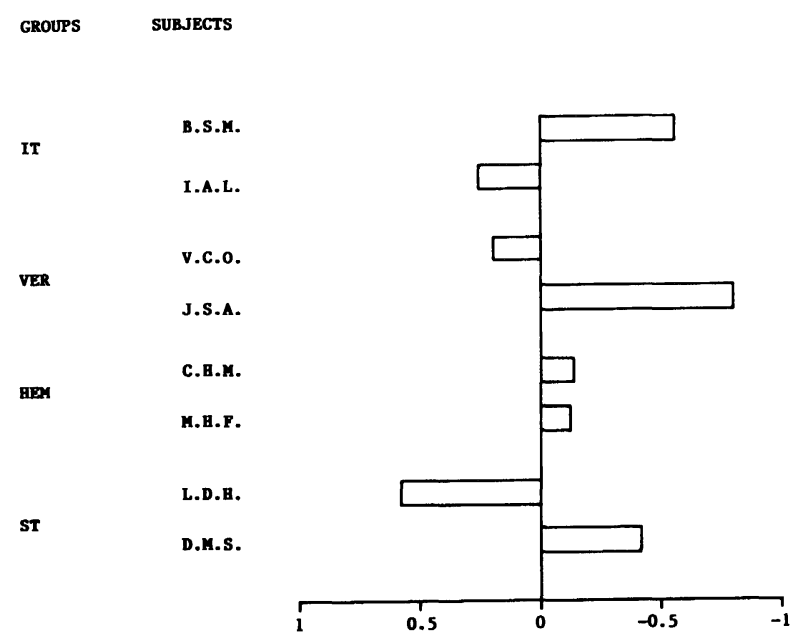

FIG. 3. Differences in visual short-term memory test between individual patients' scores and control subjects' average scores plotted in terms of S.D. units. 


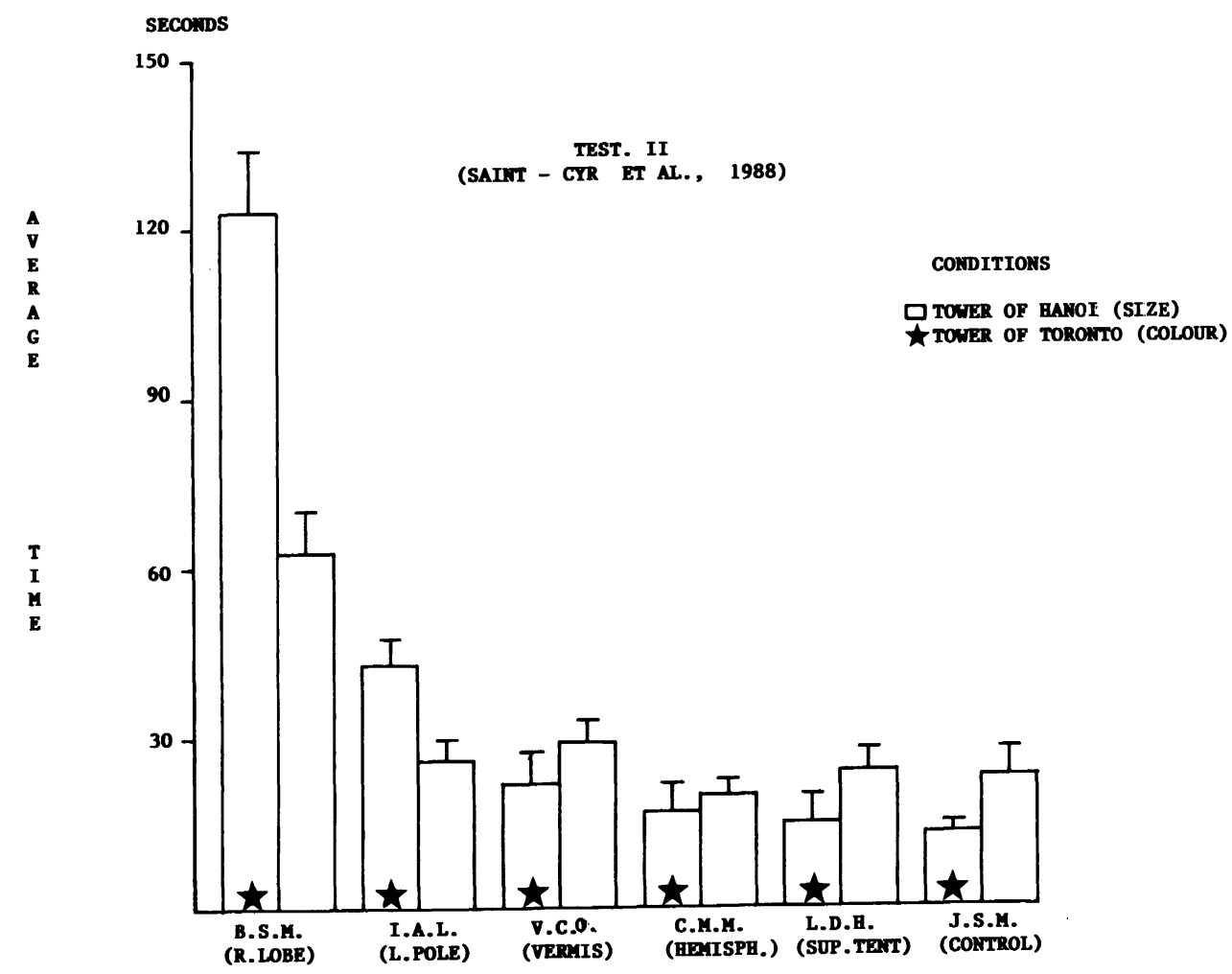

FIG. 4. Histogram showing results of I.A.L. (tumour of left temporal pole), B.S.M (tumour of right temporal lobe) and each of the subjects selected from the VER, HEM, ST and CON groups in either colour (Tower of Toronto) or size (Tower of Hanoi) procedural learning tasks (modified from Saint-Cyr et al., 1988). Each column refers to average time spent by each subject in three trials of each task.

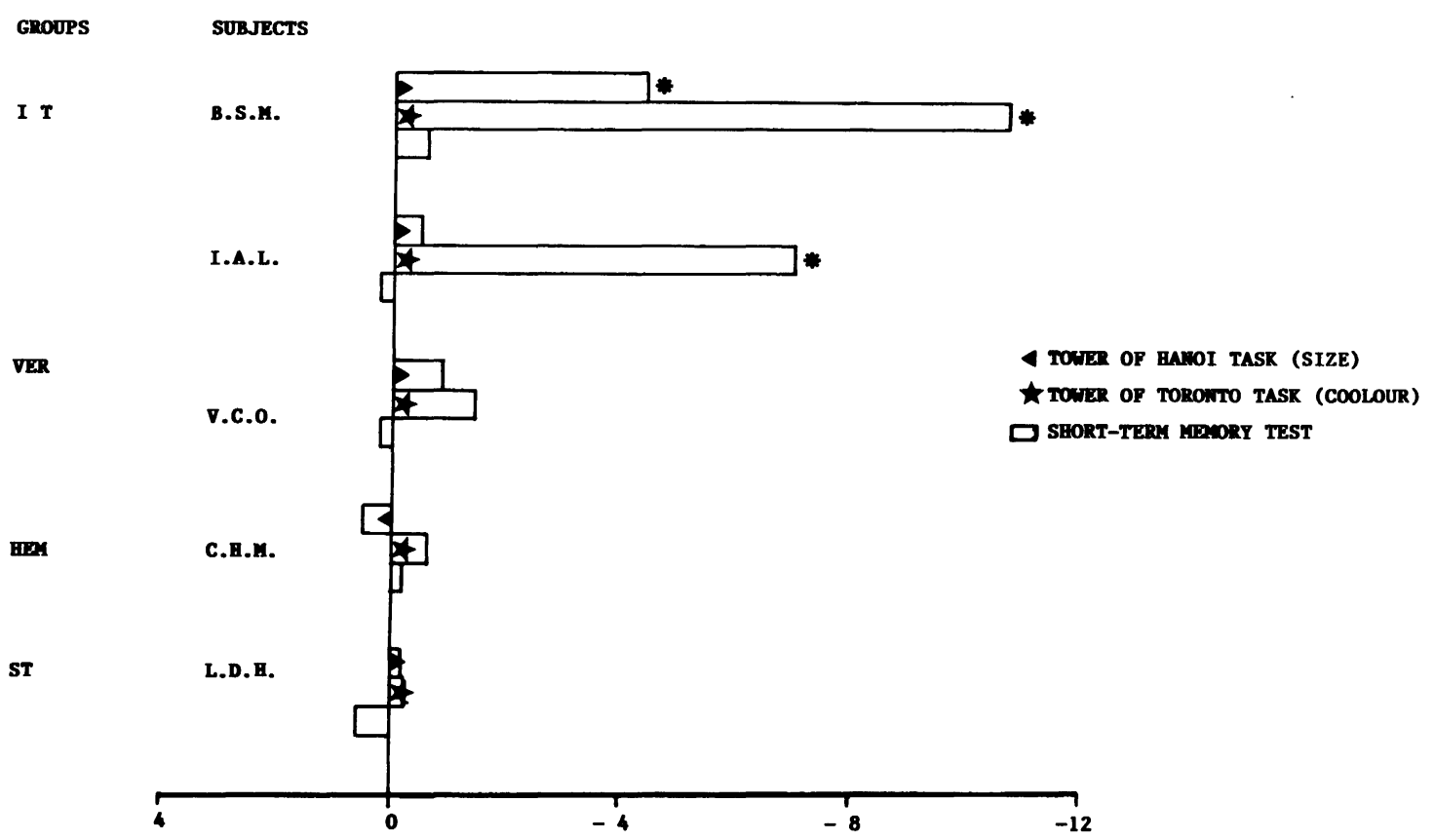

FIG. 5. Differences in the procedural learning tasks, in comparison with those obtained in the short-term memory test, between individual patients' scores and the control subjects' scores plotted in terms of S.D. units. A difference between patient and control means was considered significant $\left({ }^{*}\right)$ when it fell more than 2.6 S.D.s $(P<0.01)$ beyond normal values. Note that scale proportions here are larger than in Fig. 3. 
amygdalofugal pathway (Yakovlev, 1948). The dorsomedial (DM) and the ventral anterior (VA) nuclei of the thalamus further communicate with the prefrontal cortex, which also sends afferent pathways to TE, through the uncinate fascicle, and to the striosomes of the caudate nucleus. The striosomes then connect with the substantia nigra reticulata, which has afferent outputs to DM and VA. This prefronto-caudate-striosomal loop has been incriminated in procedural learning deficits of some Huntington's disease patients (Saint-Cyr et al., 1988). Moreover, Miyachi and his group (1994) have found that blockade of the head of the caudate in macaques causes deficits in procedural learning too.

The caudate and the putamen receive input from most of the cerebral cortex, including IT, and the two nuclei project to the globus pallidus and associated structures within the extrapyramidal system (Turner et al., 1980; Van Hoesen et al., 1981). Visual-pattern discrimination habits, which are not affected by limbic lesions, are markedly affected by damage along this cortico-striatal pathway. Thus, pattern discrimination learning and retention can be impaired by lesions either of IT cortex (Mishkin, 1954) or of some of the striatal regions to which this cortex projects, including the tail of the caudate (Divac et al., 1967) and the ventral portion of the putamen (Buerger et al., 1974). In the present study we were able to analyse impairment of colour discrimination learning circumscribed to the IT cortex.

Komatsu and Ideura (1993) have recorded the activity of IT neurones of macaques while they performed a visual fixation task, and have analysed their selectivity for colour, contour shape and textural pattern of coloured geometrical patterns. They noticed that of the large percentage of cells which responded to one or more stimuli, $69 \%$ were selective for colour, $68 \%$ for shape and $82 \%$ for pattern, and that the colour preference of individual cells did not seem to depend on shape or pattern of stimuli. Therefore, their results provide information that signals from different visual modalities are extensively integrated at the IT cortex, but that sensitivities for chromatic and spatial parameters of visual stimuli may be separately generated and assigned at random to individual IT neurones.

There was an evident floor effect in the average time spent by the selected subjects of the VER, HEM, ST and CON groups in both procedural learning tasks. Due to this effect the differences found in the Tower of Hanoi (size) task between I.A.L., of the IT group, and J.S.M., of the CON group, may not have reached significance. Nevertheless, Olshausen and his associates (1993) have proposed that 'form' perception, which is mainly concerned with object identification, regardless of position or size, involves a parvocellular pathway going from V1, in the striate area, to V2 and V4, in the extrastriate area, and from there to IT cortex, and that 'where' perception, which is concerned with location and spatial relationships among objects, regardless of their identity, involves a magnocellular pathway going from V1 to V2, and from there to $\mathrm{MT}$, or middle temporal area in the upper temporal lobe, and finally to $\mathrm{PP}$, or posterior parietal complex. Using functional magnetic resonance imaging, other investigators (Tootell et al., 1995) have, indeed, found that MT in humans is an area more active in size and movement perception and less in colour perception. Thus, the lack of significance in the differences found could have an entirely distinct explanation referring to separate pathways involved either in object identification, such as its colour, or in object location in space, such as its size, in the visual modality, and to damage mainly of the first pathway in one IT subject, I.A.L., of the present study. On the other hand, unilateral damage that included at least part of the MT area of the right temporal lobe of the other IT subject, B.S.M., appeared to lead this subject to manifest significant deficits in the Tower of Hanoi (size) task. In this regard, the studies of Cheng and his group (1994) on activity of visual extrastriate areas have disclosed that V4 and MT neurones of macaques show similar inhibition by long bars. However, V4 neurones of this animal seem to prefer stimuli whose lengths are distributed along the lengths of the receptive fields, whereas MT neurones prefer stimuli with shorter lengths. Furthermore, MT neurones of macaques are slightly more sensitive to luminance contrasts than V4 cells. Evidently, more research is needed in order to obtain an accurate representation of the activity of neurones of brain areas connected to IT.

Although results of subjects with inferior temporal tumoral lesions in the short-term memory test of the present study were not significantly different from those of subjects of the control group, other studies with humans (Cacace et al., 1992) and with macaques (Sobotka and Ringo, 1993; Miller and Desimone, 1994) have found that activity related to visual shortterm recognition memory seems to be present in cells of this cortical area. One possible explanation for the results obtained in the present study may be that the test employed was too simple and brief to allow for a thorough investigation of visual short-term memory. Sobotka and Ringo (1993) used an image presentation test with one macaque. Among other things, 
they found a decreased response of inferior temporal cells upon image repetition, which additionally indicates the presence of activity in these cells critical for long-term memory. Such activity was evident in responses recorded from a few seconds to at least $1 \mathrm{~h}$ after presentation of more familiar images. The latter authors consider that this response may have been particularly strong due to months of training of their monkey. Miller and Desimone (1994) have also found that there appears to be a differential response of neurones of this area in macaques, which may be either automatic or volitional, to repeated presentations of a stimulus in a sequence of pictures. According to Miller (Miller et al., 1991, 1993), use of a delayed matching-to-sample test, employing multiple intervening items between presentation of sample stimulus and presentation of matching test stimulus, with these subjects still leads to a suppression of the responses to matching stimuli. The suppressive effects appear to be generated within or before IT cortex because the decrement of responses to matching stimuli begins almost immediately with the onset of the visual response. Finding out more about the existence of these effects among human subjects will probably require prolonging the duration and increasing the complexity of the intervening distractor task in future applications of the short-term memory test employed in the present study. Also, testing human subjects with delayed non-matching-tosample techniques (Overman et al., 1991) utilized in analysing visual short-term memory should be considered for future research in this area. A further possibility is, of course, that activity of neurones of the superior temporal cortex, which was not damaged in one (I.A.L.) and only indirectly and unilaterally damaged in the other (B.S.M.) of our IT subjects, and which is also involved in visual short-term recognition memory (Cacace et al., 1992), and activity of neurones of the undamaged frontal cortex of both sides of the brain may have assisted these subjects in carrying out the short-term memory test of the present study.

In summary, unilateral damage to IT cortex in either of the inferior temporal lobes of the brain in humans appears to produce significant deficits in procedural learning tasks involving differences in colour of objects, i.e. differences in one of the features, colour, pattern, shape, etc., characteristic of visual stimuli. Similar unilateral damage to MT cortex in the superior temporal lobes may also produce deficits in procedural learning tasks involving differences in size of objects, i.e. relative differences, in size, position, etc., between two or more visual stimuli. On the other hand, tests employed to assess mechanisms related to visual short-term recognition and recall memory must be designed to tax different areas of the brain, inferior temporal cortex, superior temporal cortex, frontal cortex, etc., to be able to detect significant memory deficits in humans.

\section{Acknowledgements}

We would like to thank Mr Heriberto Azpeitia-Mendoza for drawing the graphs of Figs 2, 3, 4 and 5 and for producing the photographs for this manuscript.

\section{REFERENCES}

Baizer JS, Ungerleider LG and Desimone R (1991) Subcortical connections of inferior temporal cortex and posterior parietal cortex in macaques. Society of Neuroscience Abstracts, 18, 845.

Boucher J and Lewis V (1989) Memory impairments and communication in relatively able autistic children. Journal of Child Psychology and Psychiatry, 50, 99-122.

Buerger AA, Gross CG and Rocha-Miranda CE (1974) Effects of ventral putamen lesions on discrimination learning by monkeys. Journal of Comparative Psychology and Psychiatry, 86, 440-446.

Cacace AT, McFarland DJ, Emrich JF and Haller JS (1992) Assessing short-term recognition memory with forced choice psychophysical methods. Journal of Neuroscience Methods, 44, 145-155.

Cheng K, Hasegawa T, Saleem KS and Tanaka K (1994) Comparison of neuronal selectivity for stimulus speed, length, and contrast in the prestriate visual cortical areas V4 and MT of the Macaque monkey. Journal of Neurophysiology, 71, 2269-2280.

Corbetta M, Miezin FM, Dobmeyer S, Shulman GI and Petersen SE (1991) Selective and divided attention during visual discrimination of shape, colour, and speed: Functional anatomy by positron emission tomography. Journal of Neuroscience, 11, 2383-2402.

Divac Y, Rosbold HE and Szwarcbart MK (1967) Behavioural effects of selective ablation of the caudate nucleus. Journal of Comparative Physiology and Psychiatry, 63, 184-190.

Hudson LJ (1990) Speech and language disorders in childhood brain tumours. In: Acquired Neurological Speech/Language Disorders in Childhood (Ed. BE Murdoch), pp. 245-268. Taylor and Francis, London.

Kim S-G, Ugurbil K and Strick PL (1994) Activation of a cerebellar output nucleus during cognitive processing. Science, 265, 949-951.

Komatsu H and Ideura Y (1993) Relationships between color, shape, and pattern selectivities of neurons in the inferior temporal cortex of the monkey. Journal of Neurophysiology, 70, 677-694.

Lazareff JA and Castro-Sierra E (1991) Memory deficits in young subjects with cerebellar tumors. Society of Neuroscience Abstracts, 17, 1024.

Miller EK and Desimone R (1994) Parallel neuronal mechanisms for short-term memory. Science, 263, 520-522.

Miller EK, Lin L and Desimone R (1991) A neural mechanism for working and recognition memory in inferior temporal cortex Science 254, 1377-1379. 
Miller EK, Lin L and Desimone R (1993) Activity of neurons in anterior inferior temporal cortex during a shortterm memory task. Journal of Neuroscience, 13, 1460-1478.

Mishkin M (1954) Visual discrimination performance following partial ablations of the temporal lobe: II. Ventral surface vs. hippocampus. Journal of Comparative Physiology and Psychiatry, 47, 187-193.

Mishkin M (1982) A memory system in the monkey. Philosophical Transactions of the Royal Society, London B298, 85-95.

Mishkin M and Appenzeller T (1987) The anatomy of memory. Scientific American, 256, 80-89.

Mishkin M and Petri HL (1984) Memories and habits: Some implications for the analysis of learning and retention. In: Neuropsychology of Memory (Eds LR Squire and N Butters), pp. 287-296. Guilford Press, New York.

Mishkin M, Malamut B and Bachevalier J (1984) Memories and habits: Two neural systems. In: Neurobiology of Learning and Memory (Eds G Lynch, JL McGaugh and NM Weinberger), pp. 65-77. Guilford Press, New York.

Miyachi S, Miyashita K, Karadi Z and Hikosaka O (1994) Effects of blockade of monkey basal ganglia on the procedural learning and memory. Society of Neuroscience Abstracts, 20, 357.

Miyashita Y (1993) Inferior temporal cortex: Where visual perception meets memory. Annual Review of Neuroscience, 16, 245-263.

Nielsen-Bohlman L and Knight RT (1994) Event-related potentials dissociate immediate and delayed memory. In: Cognitive Electrophysiology: Basic and Clinical Research (Eds HJ Heinze, TF Munte and GR Mangun), pp. 169-183. Birkhauser, Boston.

Olshausen BA, Anderson CH and van Essen DC (1993) A neurobiological model of visual attention and invariant pattern recognition based on dynamic routing of information. Journal of Neuroscience, 13, 4700-4719.

Overman WH, Miller M, Moore K, Kilpatrick W and Rogers C (1991) Use of an oddity task in children to analyze the solution of delayed non-matching to sample. Society for Neuroscience Abstracts, 17, 1044.

Raven JC, Court JH and Raven J (1986) Manual for Raven's Progressive Matrices and Vocabulary Scales (Section 2 Coloured Progressive Matrices). Lewis, London.

Roland PE, Gulyás B, Seitz RJ, Böhm C and Stone-Elander J (1990) Functional anatomy of storage, recall, and recognition of a visual pattern in man. Neuroreport, $\mathbf{1}$, 53-56.

Saint-Cyr JA, Taylor AE and Lang AE (1988) Procedural learning and neostriatal dysfunction in man. Brain 111, 941-959.

Sobotka S and Ringo JL (1993) Investigation of long-term recognition and association memory in unit responses from inferotemporal cortex. Experimental Brain Research, 96, 28-38.

Tootell RBH, Reppas JB, Kwong KK, Malach R, Born RT, Brady TJ, Rosen BR and Bellivau JW (1995) Functional analysis of human MT and related visual cortical areas using magnetic resonance imaging. Journal of Neuroscience, 15, 3215-3230.

Turner B, Mishkin M and Knapp M (1980) Organization of the amygdalopetal projections from modality-specific cortical associations in the monkey. Journal of Comparative Physiology, 191, 515-543.

Ungerleider LG and Mishkin M (1982) Two cortical visual systems. In: Analysis of Visual Behavior (Ed. DJ Ingle), pp. 549-586. MIT Press, Cambridge, MA.

Van Hoesen GW, Yeterian EH and Lavizzo-Mourey R (1981) Widespread corticostriate projections from temporal cortex of the rhesus monkey. Journal of Comparative Neurology, 199, 205-219.

Wechsler D (1974) Manual for the Wechsler Intelligence Scale for Children-Revised. The psychological Corporation, San Antonio.

Yakovlev PI (1948) Motility, behavior and the brain: Stereodynamic organization and neural coordinates of behavior. Journal of Nervous and Mental Diseases, 107, 313-335. 


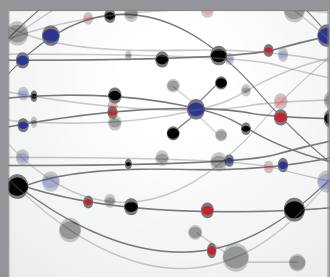

The Scientific World Journal
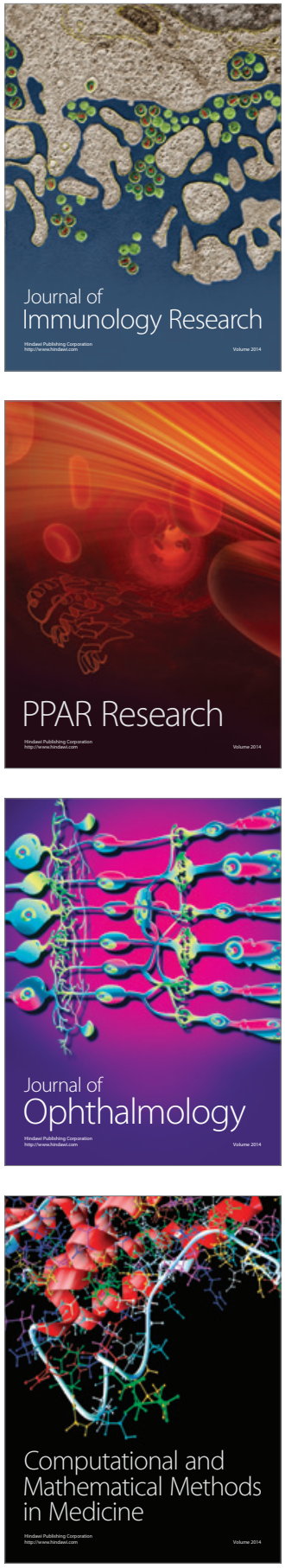

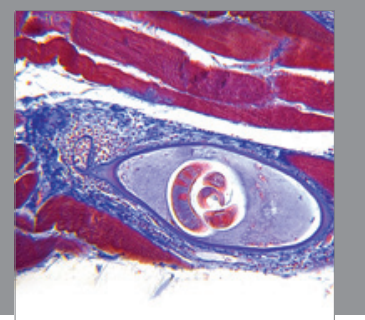

Gastroenterology

Research and Practice
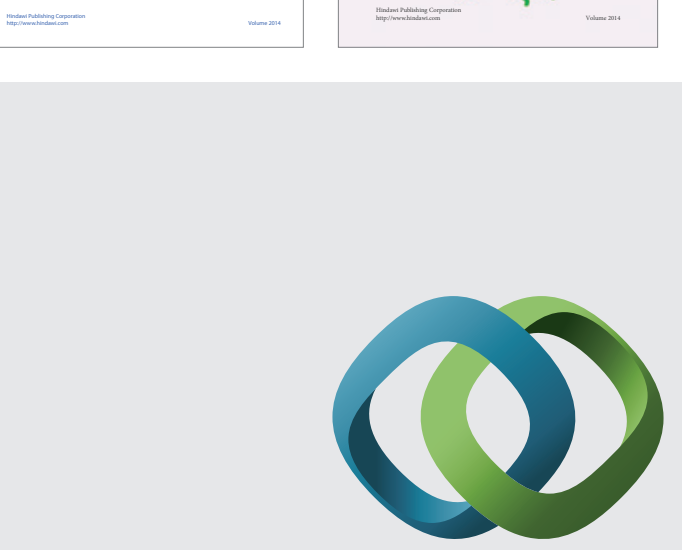

\section{Hindawi}

Submit your manuscripts at

http://www.hindawi.com
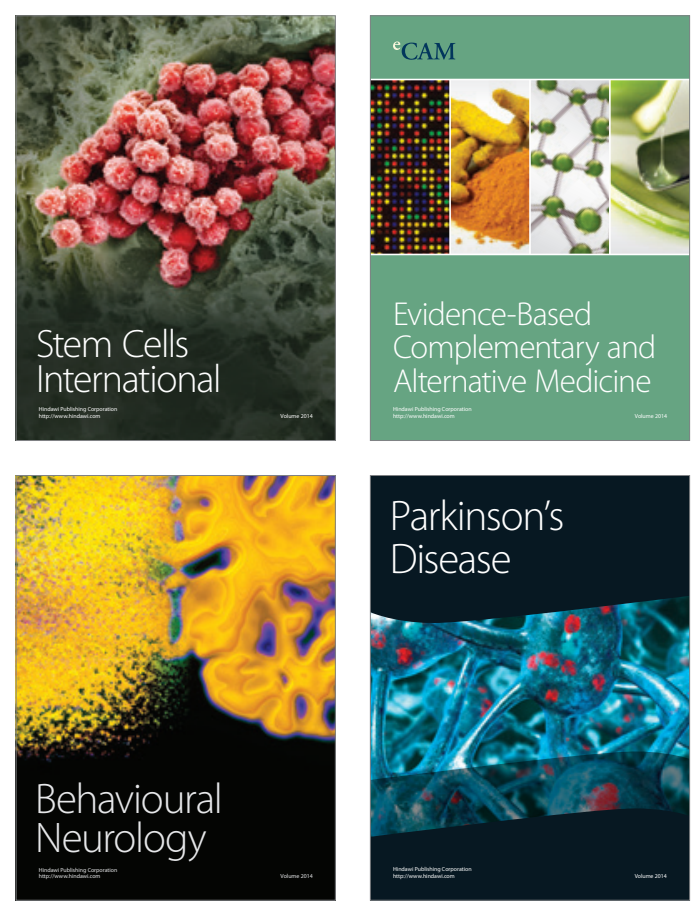

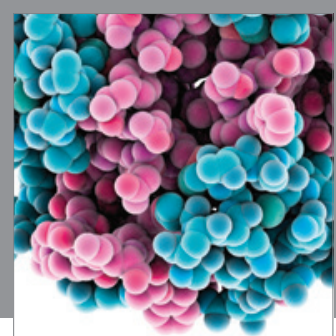

Journal of
Diabetes Research

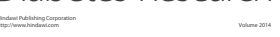

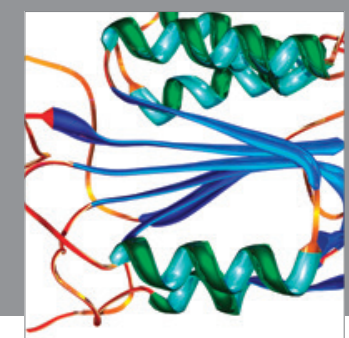

Disease Markers
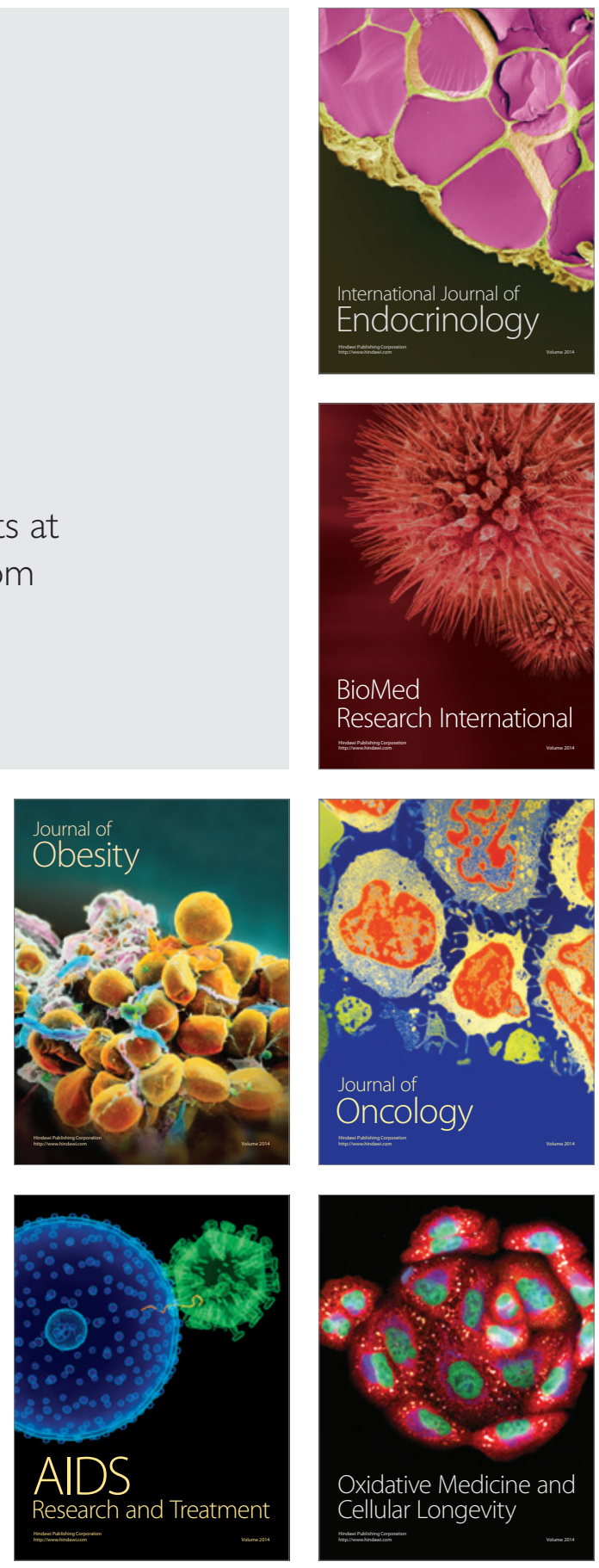